University of Wollongong

Research Online

Faculty of Engineering and Information

Faculty of Engineering and Information

Sciences - Papers: Part A

Sciences

$1-1-2016$

\title{
Simultaneous grain growth and grain refinement in bulk ultrafine-grained copper under tensile deformation at room temperature
}

Hai Liang Yu

University of Wollongong, hailiang@uow.edu.au

Cheng Lu

University of Wollongong, chenglu@uow.edu.au

Anh Kiet Tieu

University of Wollongong, ktieu@uow.edu.au

Hui Jun Li

University of Wollongong, huijun@uow.edu.au

Ajit R. Godbole

University of Wollongong, agodbole@uow.edu.au

See next page for additional authors

Follow this and additional works at: https://ro.uow.edu.au/eispapers

Part of the Engineering Commons, and the Science and Technology Studies Commons

Research Online is the open access institutional repository for the University of Wollongong. For further information contact the UOW Library: research-pubs@uow.edu.au 


\title{
Simultaneous grain growth and grain refinement in bulk ultrafine-grained copper under tensile deformation at room temperature
}

\author{
Abstract \\ Grain growth and grain refinement behavior during deformation determine the strength and ductility of \\ ultrafine-grained materials. We used asymmetric cryorolling to fabricate ultrafine-grained copper sheets \\ with an average grain width of $230 \mathrm{~nm}$ and having a laminate structure. The sheets show a high-true \\ failure strain of 1.5. Observation of the microstructure at the fracture surface reveals that ultrafine \\ laminate-structured grains were simultaneously transformed into both equiaxed nanograins and coarse \\ grains under tensile deformation at room temperature.

\section{Keywords} \\ deformation, tensile, under, temperature, copper, room, grained, ultrafine, bulk, refinement, growth, grain, \\ simultaneous

\section{Disciplines} \\ Engineering | Science and Technology Studies

\section{Publication Details} \\ Yu, H., Lu, C., Tieu, A. Kiet., Li, H., Godbole, A., Kong, C. \& Zhao, X. (2016). Simultaneous grain growth and \\ grain refinement in bulk ultrafine-grained copper under tensile deformation at room temperature. \\ Metallurgical and Materials Transactions A: Physical Metallurgy and Materials Science, 47A 3785-3789.

\section{Authors} \\ Hai Liang Yu, Cheng Lu, Anh Kiet Tieu, Hui Jun Li, Ajit R. Godbole, Charlie Kong, and Xing Zhao
}




\title{
Simultaneous Grain Growth and Grain Refinement in Bulk Ultrafine-Grained
}

\section{Copper under Tensile Deformation at Room Temperature}

\author{
HAILIANG YU ${ }^{1, *}$, CHENG LU ${ }^{1}$, ANH KIET TIEU ${ }^{1}$, HUIJUN LI ${ }^{1, *}$, AJIT GODBOLE ${ }^{1}$, \\ CHARLIE KONG ${ }^{2}$, and XING ZHAO ${ }^{3,1}$
}

1. School of Mechanical, Materials \& Mechatronics Engineering, University of Wollongong, NSW 2500, Australia; 2. Electron Microscope Unit, University of New South Wales, Sydney, NSW 2052, Australia; 3. State Key Laboratory of High Performance Complex Manufacturing, Central South University, Changsha 410083, China

\begin{abstract}
Grain growth and grain refinement behavior during deformation determines the strength and ductility of ultrafine-grained materials. We used asymmetric cryorolling to fabricate ultrafine-grained copper sheets with an average grain width of $230 \mathrm{~nm}$ and having a laminate structure. The sheets show a high true failure strain of 1.5. Observation of the microstructure at the fracture surface reveals that ultrafine laminate-structured grains were simultaneously transformed into both equiaxed nano grains and coarse grains under tensile deformation at room temperature.
\end{abstract}

Keywords: grain growth; grain refinement; ultrafine grain; copper; ductility

For most materials, strength and ductility are conflicting properties. However, with improvement in the strength of ultrafine-grained (UFG)/nano-grained (NG) materials,

Corresponding author: YU H.L., yuhailiang1980@tom.com, hailiang@uow.edu.au

LI H.J., huijun@uow.edu.au 
there is widespread interest in attempts to simultaneously improve the ductility. ${ }^{[1]} \mathrm{A}$ number of techniques to develop UFG materials with both high strength and high ductility have been proposed. ${ }^{[2-6]}$ Recently, $\mathrm{Lu}^{[7]}$ reported a gradient copper with high strength and high ductility. He suggested that the deformation of nano-gradient copper is dominated by a mechanically driven grain boundary migration with concomitant grain coarsening and softening. He proposed that deformed coarse grains are hardened by dislocation slip and accumulations, providing work hardening of the global sample. He proposed theoretically that in a critical sub-micro-sized region, neither hardening nor softening is induced as the two mechanisms are balanced. The aforementioned studies refer to theoretical prediction. However, to date there is no experimental verification of the simultaneous occurrence of grain growth and grain refinement in bulk UFG materials under tensile deformation.

Coarse grains can be refined under increased strain at room temperature and reach a stable size due to dynamic recovery, if the strain exceeds a certain threshold value. ${ }^{[8]}$ At the same time, grain growth has also been observed in thin films. ${ }^{\left[{ }^{[-11]}\right.}$ Apart from the grain growth driven by temperature, shear stress could bring about grain boundary migration and grain rotation, resulting in grain growth. Legros et al ${ }^{[9]}$ observed that grain growth occurs preferentially under the applied load in the highly stressed regions ahead of crack tips in NG aluminum films. They also reported very large grain boundary velocities, exceeding $200 \mathrm{~nm} \mathrm{~s}^{-1}$ for collapsing small grains and exceeding $30 \mathrm{~nm} \mathrm{~s}^{-1}$ for growing grains. Jin et al ${ }^{[10]}$ studied the in-situ deformation-induced grain growth of UFG Al films during nano-indentation at room temperature. 
Mompiou et al ${ }^{[11]}$ studied the grain boundary migration due to shear in $\mathrm{Al}$ polycrystals using a transmission electron microscope (TEM). The deformation associated with grain boundary migration was measured using the superposition of surface markers, which shows a coupling between shear and migration. Using atomistic simulations, Romero et al ${ }^{[12]}$ demonstrated that during sliding, the $\mathrm{NG}$ grains on the contact interface self-organize through extensive grain growth and lattice rotation until an optimal plastic slip orientation is established. Upon cyclic deformation, grain growth at shear bands has been observed in metals with sub-micron grain size by Kwan et al. ${ }^{[13]}$ Such grain growth is often linked to the observed relationship between strain localization associated with shear banding and deformation-induced grain growth in UFG metals. When the grain size is very small, the stress gradient in the direction away from the stress concentration sites is also believed to increase the driving force for grain boundary migration within the affected regions. However, grain growth under stress in thin foils or films may not occur in bulk samples, because grain growth under stress occurs mainly in close proximity of the free surfaces. ${ }^{[14]}$ Liao et al ${ }^{[15]}$ reported that the grains grow from $30 \pm 7.5 \mathrm{~nm}$ to $129 \pm 43 \mathrm{~nm}$ in electro-deposited NG Ni during high pressure torsion (HPT), in which the grain-boundary-mediated mechanisms play a significant role in accommodating the HPT strain. Wang et al ${ }^{[16]}$ found that the HPT-induced grain growth is achieved primarily via grain rotation for grains much smaller than $100 \mathrm{~nm}$ for a NG Ni-Fe alloy.

We conducted experiments using pure $1.0 \mathrm{~mm}$-thick copper sheets. UFG/NG 
copper has been demonstrated to have good mechanical strength while retaining its good electrical conductivity. [17-19] UFG copper sheets are ideal for micro-electro-mechanical systems (MEMS). ${ }^{[20]}$ For micro-size parts used in MEMS, the sheet thickness may range from $0.001 \mathrm{~mm}$ to $0.3 \mathrm{~mm} .^{[21]}$ The asymmetric cryorolling (ACR) technique was used to fabricate UFG copper sheets, using a 4-high multifunction rolling mill with a $50 \mathrm{~mm}$ diameter work roll. The ACR is a technique that combines features of asymmetric rolling and cryorolling. The advantages of ACR are: (i) the generation of additional shear strain that contributes to grain rotation and subdivision, producing grain refinement and modification of the crystallographic texture; (ii) the suppression of dynamic recovery at extremely low temperatures, which preserves the high density of dislocations generated by the deformation. The sheets were rolled with a rolling speed ratio of 1.4 at liquid nitrogen temperature. The sheet thickness was reduced to $0.25 \mathrm{~mm}$ after three ACR passes. Tensile tests at a strain rate of $1.0 \times 10^{-3} \mathrm{~s}^{-1}$ on an INSTRON machine were used to determine the engineering stress-strain characteristics. The tensile direction was parallel to the rolling direction (RD). The microstructure of the sheets before rolling, after ACR processing and after tensile testing ${ }^{[22]}$ was analysed by TEM. A Philips CM200 field emission gun transmission electron microscope operating at $200 \mathrm{kV}$ was used to investigate the details of the microstructure of the samples. The TEM film samples were prepared using the focused ion beam (FIB) technique on an FEI xT Nova Nanolab 200 Dual-beam workstation. The FIB slices were made in the direction normal to RD. TEM images were observed in TD, and in the RD $\times$ ND plane. The 
fracture morphology was examined by a Zeiss Auriga Field Emission Scanning Electron Microscope (FESEM) operating at $20 \mathrm{kV}$, with a working distance of $5 \mathrm{~mm}$.

Figures 1(a) and 1(b) show the microstructure evolution before and after ACR processing. After ACR processing, the coarse grains were refined to ultrafine grains with a laminate structure. Figure 1(c) shows the grain width distribution in the ACR-processed samples. The mean grain width is seen to be refined to $230 \mathrm{~nm}$. Some reports have reported that the mean grain size of pure UFG pure copper after SPD processing is in the range of $10 \mathrm{~nm}$ to $400 \mathrm{~nm} .{ }^{[17,21,23-25]}$ The laminate structure is a typical microstructure induced by rolling. The laminate structure with low-angle boundaries can have better thermal stability compared to UFG materials with equiaxed microstructure. ${ }^{[26]}$ The grain growth in a copper film with equiaxed microstructure induced by electric current has been observed by Razak et al. ${ }^{[27]}$ This suggests that copper sheets with ultrafine grains and laminate structure can be better suited for micro-parts if they are used for MEMS.

Figure 1(d) shows the tensile curve for an ACR-processed copper sheet. For the UFG copper sheets, the yield stress reaches a maximum value of $425 \mathrm{MPa}$. This value is similar to the yield stress of ECAP-processed UFG copper and much higher than the yield stress of copper sheets rolled at room temperature, as reported in Ref. [28]. In addition, the uniform elongation of UFG sheets is low, which is due to the formation of ultrafine grains after severe plastic deformation. [28] However, considerable deformation occurs after necking, as has been also observed in a large number of studies. ${ }^{[17,23,28-30]}$ Figure 1(e) shows an SEM image of the fracture surface 
of the ACR-processed UFG copper sheets. On the surface, there are many deep dimples and heavy necking. Using the area reduction ratio, ${ }^{[31]}$ the true failure strain is calculated to be 1.5. The high true strain to failure and deep dimples indicates high localized ductility.

Fig. 1- (a-b) TEM images of microstructure of annealed and ACR-processed samples; (c) Grain width distribution of ACR-processed samples; (d)

\section{Engineering stress-strain curve of UFG copper; (e) SEM image of fracture surface of copper after failure.}

Figure 2 shows a TEM image of the microstructure at the fracture surface after tensile testing. A laminate structure is seen over most of the region, similar to the microstructure after ACR processing as shown in Figure 1(b). However, there are some zones with coarse grains or with equiaxed ultrafine grains near the fracture surface. In addition, there are no residual voids to be seen near the fracture surface. The phenomenon of grain growth and grain refinement in UFG $\mathrm{Cu}$ sheets by cryorolling was also observed as shown in Figure S1 and Figure S2.

Fig. 2- TEM image of grains distribution and SEM image of a FIB slice near

\section{fracture surface.}

Figure 3 shows a detail of the local zone near the fracture surface. It is obvious that both grain refinement and grain growth occur at the same time during the tensile test. As shown in Figure 1(e), the local necking zone shows severe plastic deformation. 
It is not difficult to understand the occurrence of grain refinement under severe plastic deformation. In the figure, some $230 \mathrm{~nm}$ laminate grains were refined to equiaxed grains with size $\sim 100 \mathrm{~nm}$. In the tensile test, the shear strain is oriented at about $45^{\circ} \sim 60^{\circ}$ to the rolling direction, which might make the laminated grains transform into equiaxed grains. This matches well with the value reported by Wen et al, ${ }^{[32]}$ who found that coarse copper powders attained an ultimate stable grain size of $\sim 100 \mathrm{~nm}$ during HPT at room temperature. For UFG AA5052 sheets, Yu et al ${ }^{[22]}$ investigated the grain distribution at the fracture surface and proposed a relationship between ductile fracture and grain refinement during deformation besides the void nuclear and growth. As the grains are refined to a nano size approaching the theoretical minimum achievable value, the material becomes brittle in the shear band zone. It is difficult to explain the severe necking of the UFG copper sheets in this condition, as shown in Figure 1(e). Besides the refined grains, there are also some coarse equiaxed grains of size $\sim 800 \mathrm{~nm}$. Due to the low strain rate during the tensile test, the grain growth is stress-induced while the change of temperature can be neglected. Stress-induced grain growth has been observed during SPD processing such as HPT, [15, 16, 30] ECAP+rolling ${ }^{[33]}$ and ARB+rolling ${ }^{[34]}$. However, although there are some reports on grain growth during tensile deformation, the present paper gives the first direct evidence of grain growth in bulk UFG copper sheets under tensile deformation at room temperature.

Fig. 3 - Detail of grain refinement and grain growth near fracture surface. 
Haslam et al ${ }^{[35]}$ proposed two grain growth mechanisms during the deformation: (1) growth resulting from grain rotation-induced coalescence and (2) growth due to curvature-driven grain boundary migration. During tensile deformation, severe shear deformation occurs in the necking zone. ${ }^{[36]}$ According to the Cahn-Taylor model, ${ }^{[8]}$ the shear stress along the grain boundaries determines the grain growth, in which the rate of change of total free energy $\left(\dot{F}_{\text {total }}\right)$ is described as in Eq. (1):

$$
\dot{F}_{\text {total }}=-2 \pi r\left(P_{n} v_{n}+P_{s} v_{s}\right)
$$

where $r$ is the grain radius, $P_{n}$ and $P_{s}$ are defined as driving forces for grain boundary migration and grain boundary sliding. $v_{s}$ is the grain boundary sliding speed, $v_{n}$ is the grain boundary migration speed. Here, $v_{n}=M_{n} P_{n}, v_{s}=M_{s} P_{s}$, where $M_{n}$ and $M_{s}$ are the grain boundary migration mobility and grain boundary sliding mobility. In the necking zone, the driving force increases with increasing shear stress gradient, inducing grain growth. Legros et al ${ }^{[9]}$ observed that stress-induced large grains grow at the expense of neighboring small grains. In addition, grain rotation-induced grain growth has been observed in NG materials during deformation. ${ }^{[32]}$ The coupling effect of grain rotation and grain boundary migration gives rise to the following kinematic relationship: $v_{t}=v_{s}+\beta v_{n}$. Here, $\beta=2 \tan (\theta / 2)$ is the coupling factor between grain boundary migration and grain translation, and $\theta$ is the tilt angle. ${ }^{[37]}$ Generally, it is difficult to make laminate structure grains rotate through large angles. However, the degree of disorientation of the grains in sheets produced by asymmetric rolling is low, allowing easier grain growth. As circled in Figure 3, some laminate grains are about to coalesce. In this zone, laminate grains were refined to smaller 
equiaxed grains with high dislocation density. Further increase in the shear strain may result in an instability, destroying the structure along the shear band. This would result in subsequent formation of coarse grain in the shear band under the combination of grain boundary migration and sliding and grain rotation. ${ }^{[13]}$ In addition, compared to ultrafine grains, the coarse grains can sustain larger dislocation densities, giving rise to strain hardening which can withstand more deformation. Thus, if there is a good balance between grain refinement and grain growth during tensile deformation, the materials will show both high strength and high ductility. This has been applied in nanogradient copper materials ${ }^{[7]}$ and bimodal structured NG copper materials. ${ }^{[33]}$ For nanogradient copper, $\mathrm{Lu}{ }^{[7]}$ pointed that in a critical submicrosized region, neither hardening nor softening is induced as grain growth and grain refinement are balanced, corresponding to the strain-induced saturation structures, resulting in both high strength and high ductility of the material. For bimodal structured NG copper, Wang et al ${ }^{[33]}$ suggest that the inhomogeneous microstructure induces strain hardening mechanisms that stabilize the tensile deformation, leading to a high tensile ductility.

In summary, our findings demonstrate that both grain growth and grain refinement can occur simultaneously in the bulk UFG copper under tensile deformation at room temperature. This effect was observed in UFG copper sheets fabricated by asymmetric cryorolling with rolling speed ratio 1.4 and cooled by liquid nitrogen. We believe that a good balance between grain growth and grain refinement in UFG materials during deformation will result in both high strength and high ductility. In addition, deformation-induced grain growth and grain refinement occurred simultaneously in 
the neighboring areas. This could be the focus of further studies.

\section{Acknowledgements}

Supported by URC small grant at the University of Wollongong and the Open

Research Fund of Key Laboratory of High Performance Complex Manufacturing,

Central South University.

\section{References}

1. R.O. Ritchie: Nature Mater., 2011, vol.10, pp. 817-22.

2. K.S. Kumar, H. Van Swygenhoven, S. Suresh: Acta Mater, 2003, vol.51, pp. 5743-74.

3. Y.H. Zhao, X.Z. Liao, S. Cheng, E. Ma, Y.T. Zhu: Adv. Mater., 2006, vol.18, pp. 2280-3.

4. K. Lu, L. Lu, S. Suresh: Science, 2009, vol.324, pp. 349-52.

5. H. Kou, J. Lu, Y. Li: Adv. Mater., 2014, vol.26, pp. 5518-24.

6. I.A. Ovid'ko, T.G. Langdon: Rev. Adv. Mater. Sci., 2012, vol.30, pp. 103-11.

7. K. Lu: Science, 2014, vol.345, pp. 1455-56.

8. Y. Lin, H. Wen, Y. Li, B. Wen, W. Liu, E.J. Lavernia: Acta Mater., 2015, vol.82, pp. 304-15.

9. M. Legros, D.S. Gianola, K.J. Hemker: Acta Mater., 2008, vol.56, pp.2280-93.

10. M. Jin, A.M. Minor, E.A. Stach, J.W. Morris Jr: Acta Mater, 2004, vol.52, pp. 5381-7.

11. F. Mompiou, D. Caillard, M. Legros: Acta Mater., 2009, vol.57, pp. 2198-209.

12. P.A. Romero, T.T. Järvi, N. Beckmann, M. Mrovec, M. Moseler: Phys. Rev. Lett., 2014, vol.113, article no. 036101.

13. C.C.F. Kwan, Z. Wang: Philos. Mag., 2013, vol.93, pp. 1065-79.

14. S. Brandstetter, K. Zhang, A. Escuadro, J.R. Weertman, H. Van Swygenhoven: Scr. Mater., 2008, vol.58, pp. 61-4.

15. X.Z. Liao, A.R. Kilmametov, R.Z. Valiev, H.S. Gao, X.D. Li, A.K. Mukherjee: Appl. Phys. Lett., 2006, vol.88, article no. 021909.

16. Y.B. Wang, J.C. Ho, X.Z. Liao, H.Q. Li, S.P. Ringer, Y.T. Zhu: Appl. Phys. Lett., 2009, vol. 94, article no. 011908.

17. E.C. Moreno-valle, M.A. Monclus, J.M. Molina-aldareguia, N. Enikeev, I. Sabirov: Metall. Mater. Trans. A, 2013, vol.44, pp. 2399-408.

18. N. Takata, S.H. Lee, N. Tsuji: Mater. Lett., 2009, vol. 63, pp. 1757-60.

19. L. Lu, Y.F. Shen, X.H. Chen, L.H. Qian, K. Lu: Science, 2004, vol.304, pp.422-6. 
20. Y. Champion, Y. Bréchet: Adv. Eng. Mater., 2010, vol.12, pp. 798-802.

21. Y.J. Li, X.H. Zeng, W. Blum: Acta Mater., 2004, vol.52, pp. 5009-18.

22. H.L. Yu, K. Tieu, C. Lu, X. Liu, M. Liu, A. Godbole, C. Kong, Q.H. Qin: Sci. Rep., 2015, vol.5, article no. 9568.

23. H. Wen, Y. Zhao, T.D. Topping, D. Ashford, R.B. Figueiredo, C. Xu, T.G. Langdon, E.J. Lavernia: Adv. Eng. Mater., 2012, vol.14, pp. 185-95.

24. X.Z. Liao, Y.H. Zhao, Y.T. Zhu, R.Z. Valiev, D.V. Gunderov: J. Appl. Phys., 2004, vol.96, pp. 636-40.

25. X.Z. Liao, Y.H. Zhao, S.G. Srinivasan, Y.T. Zhu, R.Z. Valiev, D.V. Gunderov: Appl. Phys. Lett., 2004, vol. 84, pp. 592-4.

24. X.C. Liu, H.W. Zhang, K. Lu: Science, 2013, vol.342, pp. 337-40.

25. L. Razak, T. Yamaguchi, S. Akahori, H. Hashimoto, K. Ueno: Jpn J. Appl. Phys., 2012, vol.51, article no. 05EA04.

26. R.H. Li, Z.J. Zhang, P. Zhang, Z.F. Zhang: Acta Mater, 2013, vol.61, pp. 5857-68.

27. H. Bahmanpour, A. Kauffmann, M.S. Khoshkhoo, K.M. Youssef, S. Mula, J. Freudenberger, J. Eckert, R.O. Scattergood, C.C. Koch: Mater. Sci. Eng. A, 2011, vol.529, pp. 230-6.

28. S.J. Xie, P.K. Liaw, H. Choo: J. Mater. Sci., 2006, vol.41, pp. 6328-32.

29. J.A. Sharon, H.A. Padilla, B.L. Boyce: J. Mater. Res., 2013, vol.28, pp. 1539-52.

30. H. Wen, R.K. Islamgaliev, K.M. Nesterov, R.Z. Valiev, E.J. Lavernia: Philos. Mag. Lett., 2013, vol.93, pp. 481-9.

31. Y.M. Wang, M.W. Chen, F.H. Zhou, E. Ma: Nature, 2002, vol.419, pp. 912-5.

32. H.L. Yu, K. Tieu, S. Hadi, C. Lu, A. Godbole, C. Kong: Metall. Mater. Trans. A, 2015, vol.46, pp. 869-79.

33. A.J. Haslam, D. Moldovan, V. Yamakov, D. Wolf, S.R. Phillpot, H. Gleiter, Acta Mater., 2003, vol.51, pp. 2097-112.

34. H.L. Yu, K. Tieu, C. Lu, Y. Lou, X. Liu, A. Godbole, C. Kong: Int. J. Damage Mech., 2014, vol.23, pp. 1077-95.

35. J.W. Cahn, Y. Mishin, A. Suzuki: Acta Mater., 2006, vol.54, pp. 4953-75. 


\section{Captions of Figures}

Fig. 1- (a-b) TEM images of microstructure of annealed and ACR-processed samples; (c) Grain width distribution of ACR-processed samples; (d) Engineering stress-strain curve of UFG copper; (e) SEM image of fracture surface of copper after failure.

Fig. 2 - TEM image of grains distribution and SEM image of a FIB slice near fracture surface.

Fig. 3 - Detail of grain refinement and grain growth near fracture surface.

Fig. S1-TEM image of grains distribution near fracture surface of $\mathrm{Cu}$ sheet fabricated by cryorolling.

Fig. S2 - Detail of grain refinement and grain growth near fracture surface of $\mathrm{Cu}$ sheet fabricated by cryorolling. 

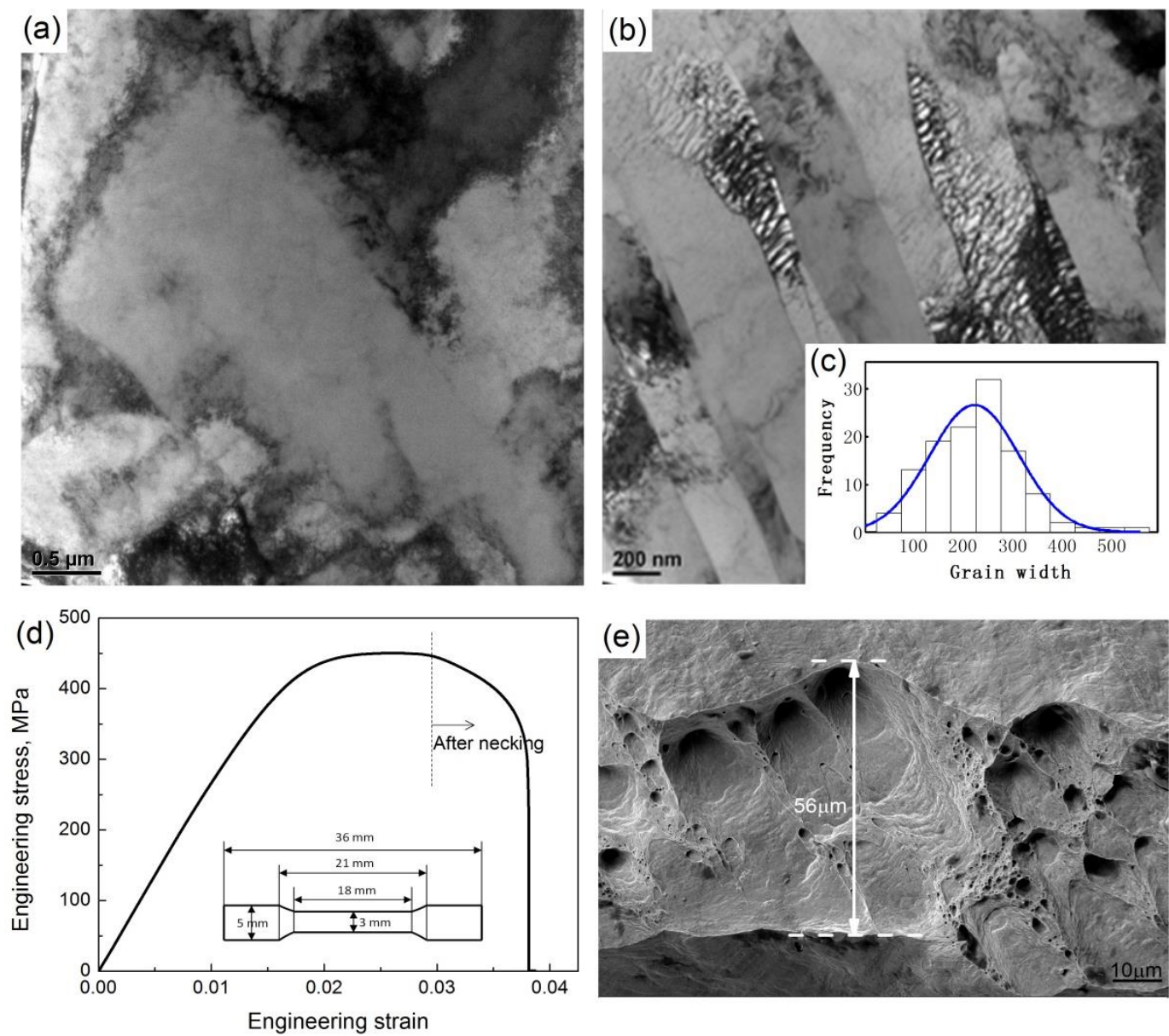

$200 \mathrm{~nm}$

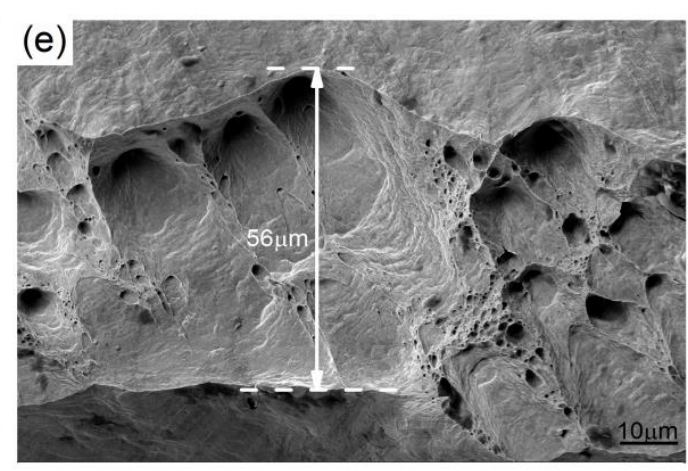

Fig. 1- (a-b) TEM images of microstructure of annealed and ACR-processed samples; (c) Grain width distribution of ACR-processed samples; (d)

Engineering stress-strain curve of UFG copper; (e) SEM image of fracture surface of copper after failure. 


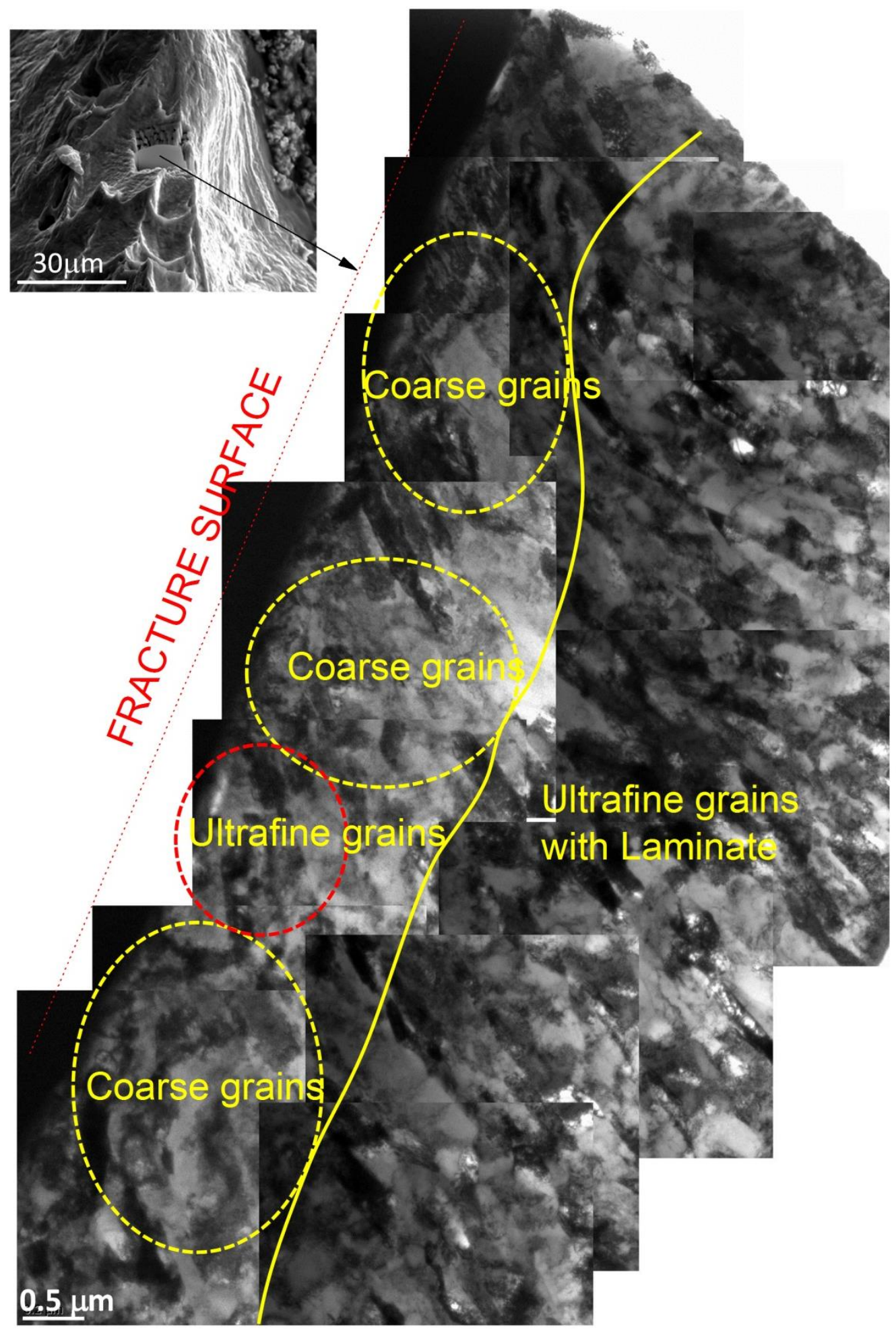

Fig. 2- TEM image of grains distribution and SEM image of a FIB slice near fracture surface. 


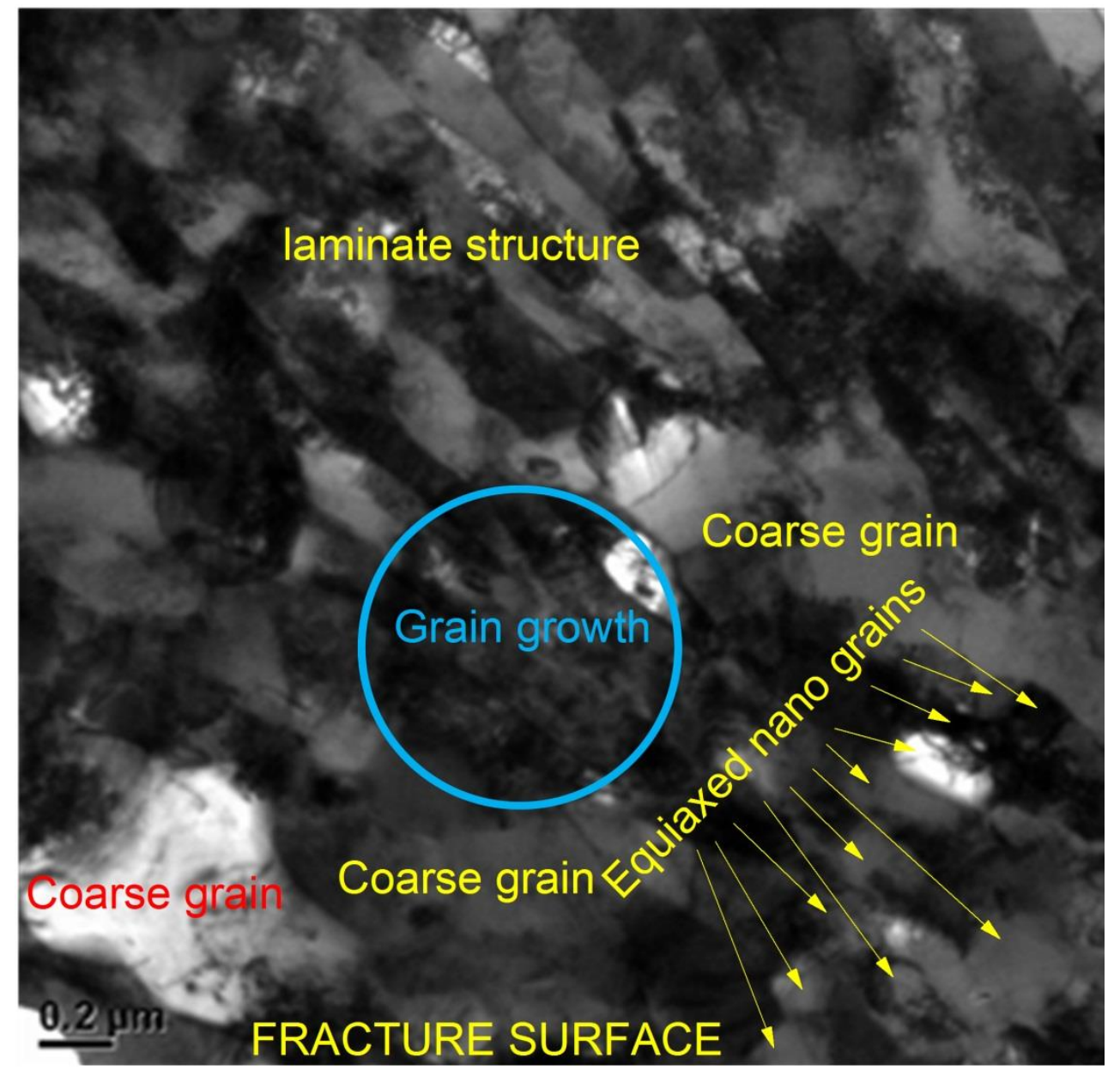

Fig. 3-Detail of grain refinement and grain growth near fracture surface. 


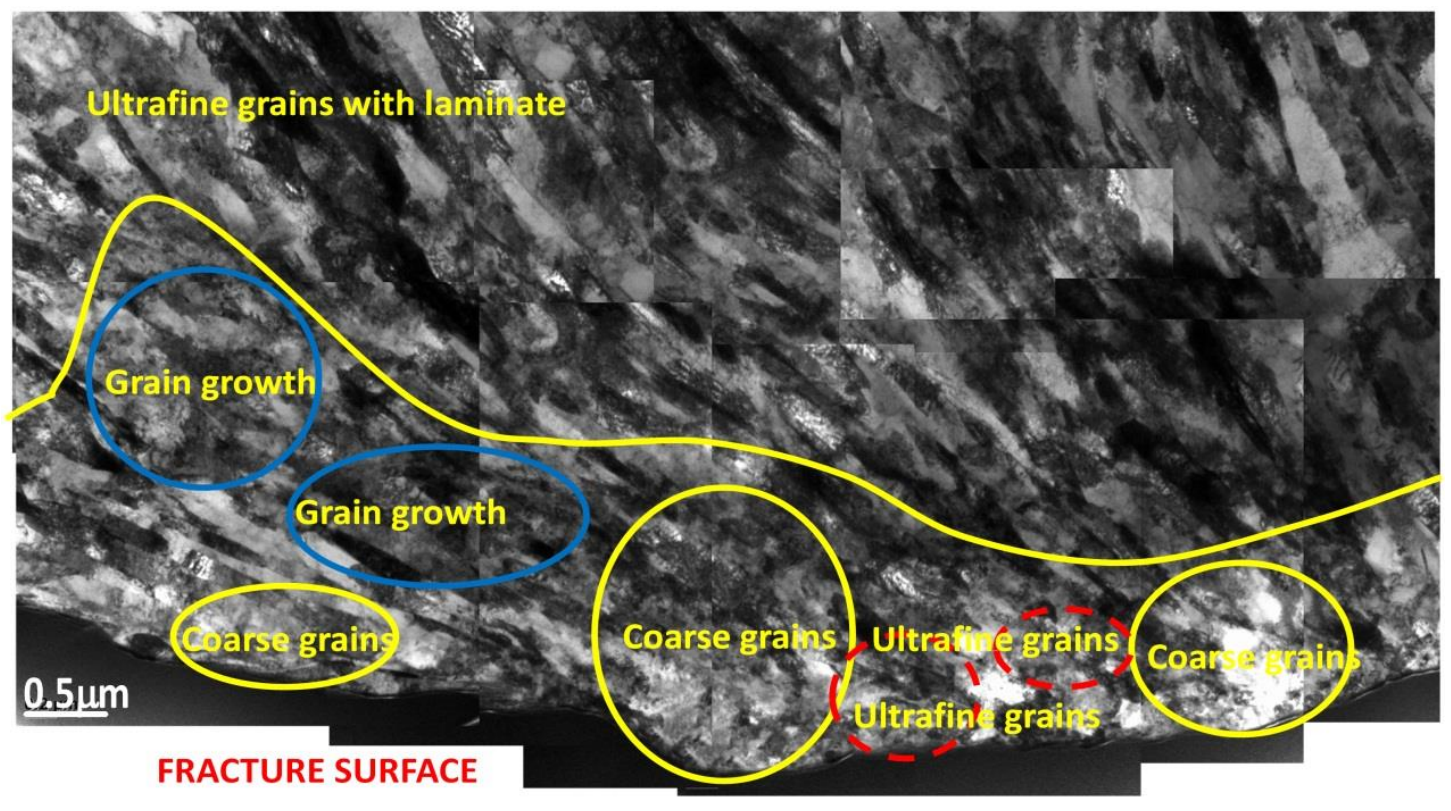

Fig. S1 - TEM image of grains distribution near fracture surface of $\mathrm{Cu}$ sheet

fabricated by cryorolling. 


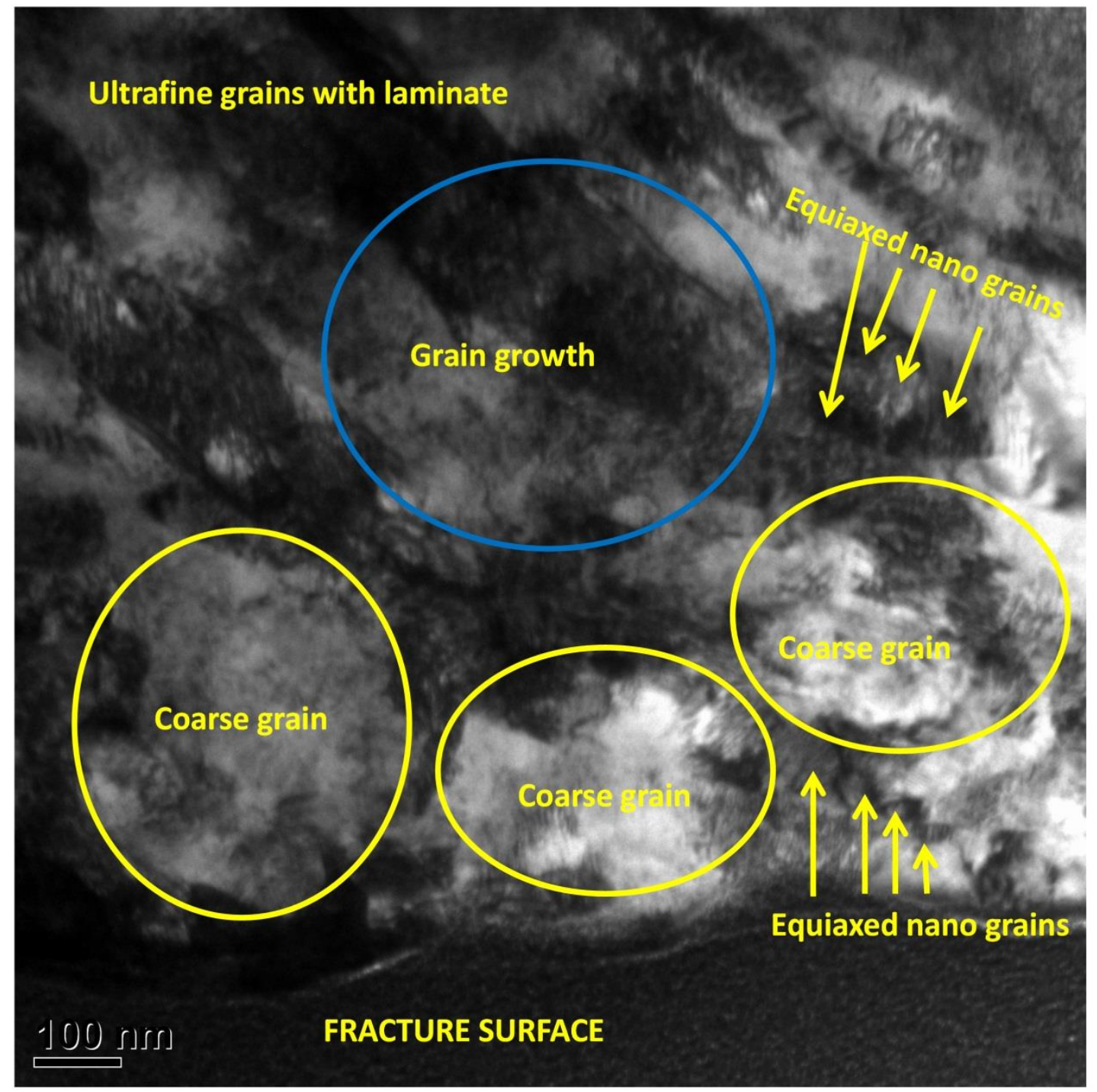

Fig. S2-Detail of grain refinement and grain growth near fracture surface of $\mathrm{Cu}$ sheet fabricated by cryorolling. 


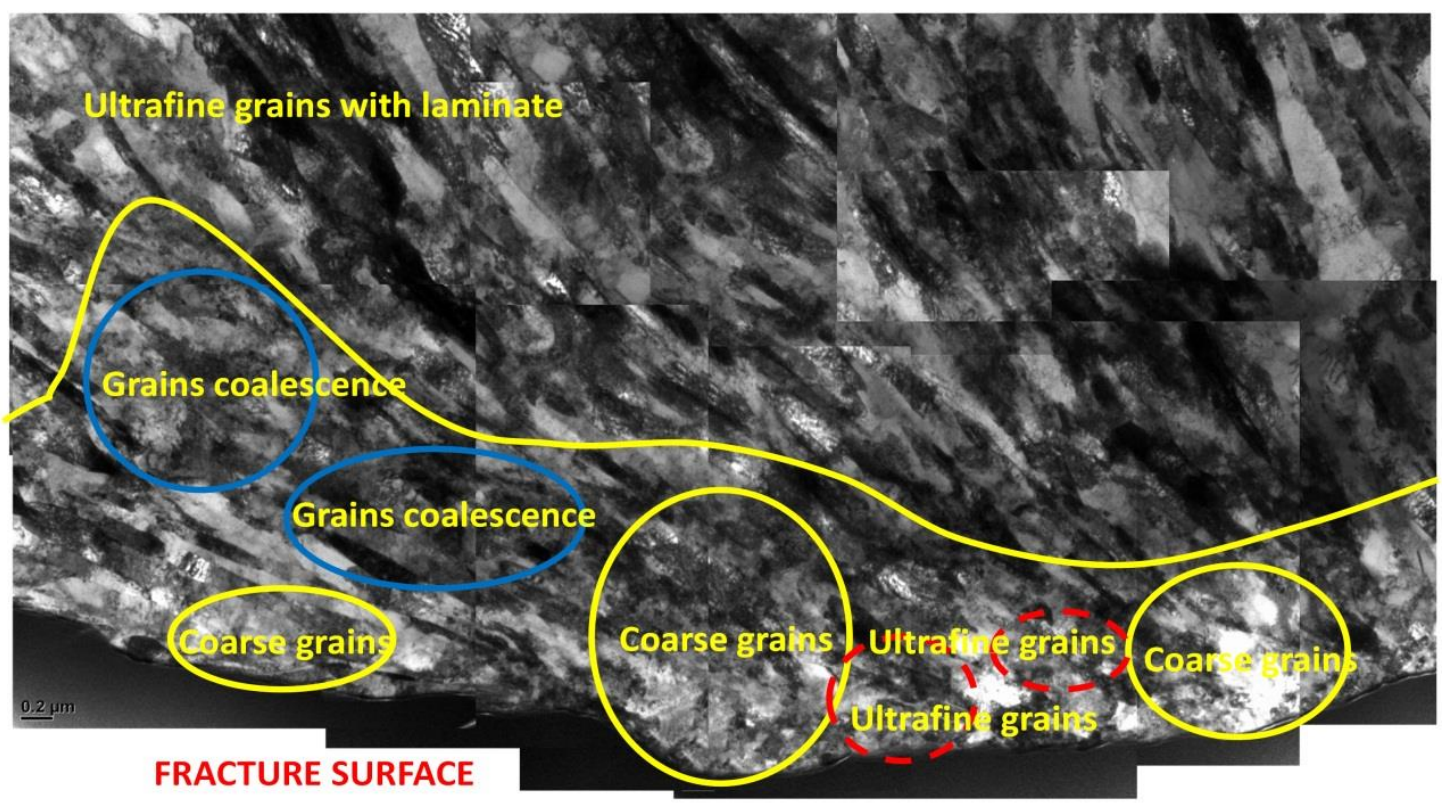

Fig. S1. TEM image of grains distribution near fracture surface of $\mathrm{Cu}$ sheet fabricated by cryorolling. 


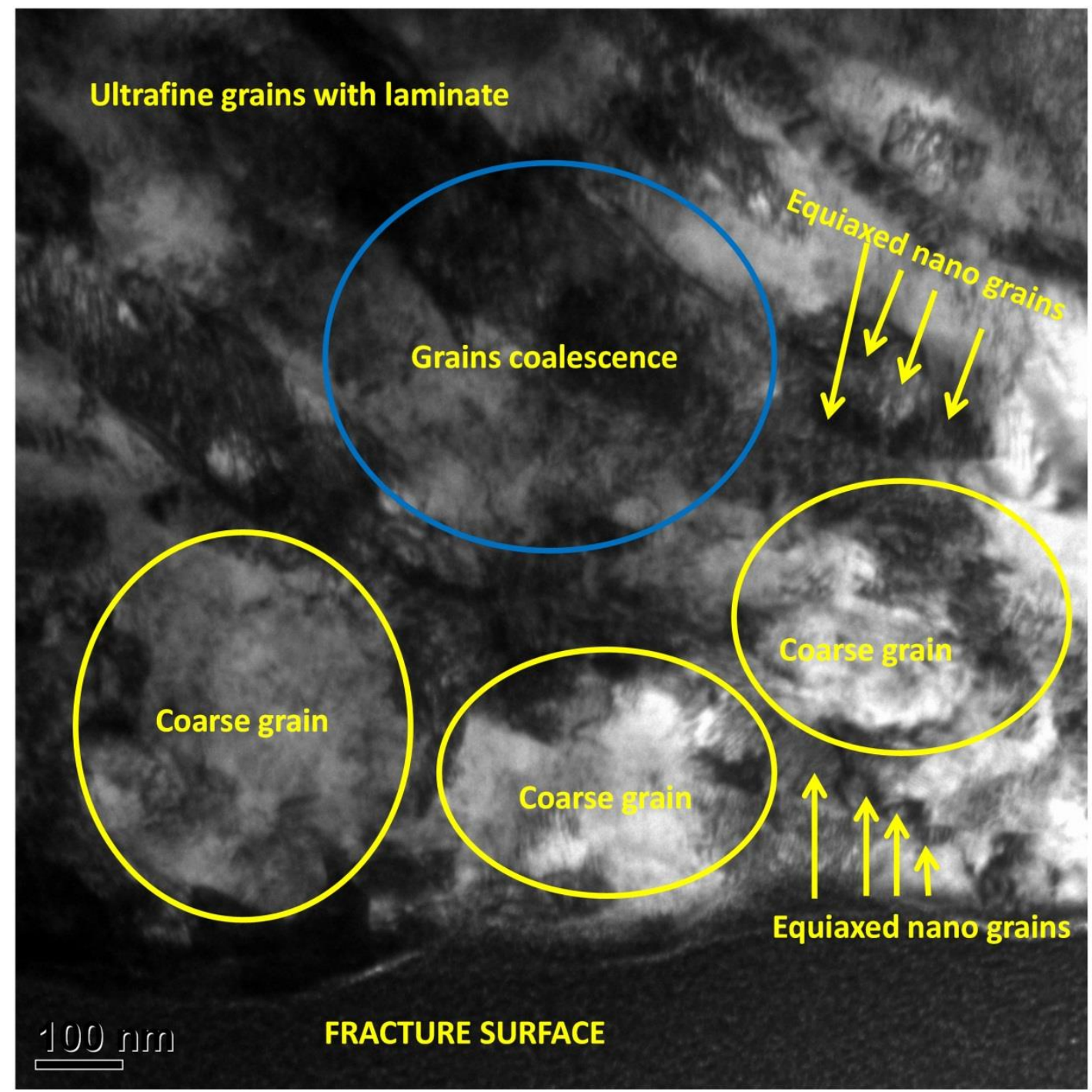

Fig. S2. Detail of grain refinement and grain growth near fracture surface of $\mathrm{Cu}$ sheet fabricated by cryorolling. 